\title{
DETECÇÃO RÁPIDA DE Salmonella ENTERITIDIS EM ALIMENTOS POR ENSAIO IMUNOENZIMÁTICO ELISA ${ }^{1}$
}

\author{
Iliana ALCOCER ${ }^{2}$, Tereza Cristina R. M. de OLIVEIRA ${ }^{2, *}$
}

\begin{abstract}
RESUMO
O método convencional de detecção de Salmonella spp., além de trabalhoso, consome longo tempo, necessitando-se normalmente de 4 a 5 dias para a confirmação da presença dessa bactéria no alimento. Portanto, o emprego de métodos rápidos e simples é importante para o diagnóstico laboratorial de toxinfecção alimentar e para o controle de qualidade. O objetivo principal deste trabalho foi a padronização de ensaio imunoenzimático-ELISA para detecção de Salmonella Enteritidis em alimentos. O ensaio utilizou anticorpos policlonais para flagelina produzidos em coelho. O anti-soro apresentou pouca reação cruzada com os sorotipos de Salmonella e as diferentes espécies de enterobactérias testadas. A sensibilidade do ensaio foi de $10^{4}$ células $/ \mathrm{mL}$, quando testado em cultivo puro. O conjugado peroxidase manteve-se estável durante dois meses a $4^{\circ} \mathrm{C}$ e o seu uso deve ser exclusivamente durante este tempo. O ensaio padronizado apresentou simplicidade e rapidez, com sensibilidade de 1 célula/25g de maionese de batata e cenoura, após enriquecimento em água peptonada tamponada durante 24 horas a $37^{\circ} \mathrm{C}$, sem necessidade de enriquecimento seletivo.

Palavras-chave: Salmonella Enteritidis; ELISA; detecção rápida.
\end{abstract}

\section{SUMMARY}

RAPID DETECTION OF SALMONELLA ENTERITIDIS IN FOOD BY ELISA ASSAY. Traditional cultural methods for the detection of Salmonella in foods is a labour-intensive and time-consuming, taking 4 to 5 days for the final results to be known. Therefore, simplified and rapid methods are required for both diagnosis of foodborne diseases and microbiological food quality control. The aim of this study was to develop an enzyme-linked immunosorbent assay (ELISA) for the detection of Salmonella Enteritidis in foods. The assay used a polyclonal detector antibody to flagelin raised in rabbit. The anti-sera obtained showed slight cross-reactions to others Salmonella serotypes and Enterobacteriaceae species tested. The method sensitivity was of $10^{4}$ cells $/ \mathrm{mL}$ of pure culture. The horseradish peroxidase conjugate was stable up to two months at $4^{\circ} \mathrm{C}$ and for this reason it should be used only during this period. The method also showed sensitivity of 1 cell per $25 \mathrm{~g}$ of potato and carrot salad containing home-made mayonnaise by using only a cultural stage in buffered peptone water incubated for 24 hours at $37^{\circ} \mathrm{C}$. In conclusion, the method showed to be practical and reliable to detect Salmonella Enteritidis in foods.

Keywords: Salmonella Enteritidis; ELISA; rapid detection.

\section{1 - INTRODUÇÃO}

A salmonelose humana ocorre, principalmente, devido ao consumo de alimentos e água contaminados com Salmonella spp. Vários alimentos já foram associados a esta infecção. Entretanto, nos últimos anos observou-se em todo o mundo, um aumento de salmonelose humana devido ao sorotipo Enteritidis, relacionado com o consumo de frango, ovos e derivados [10, 11].

O método convencional de detecção de Salmonella em alimentos envolve etapas de cultura dispendiosas e trabalhosas, consome longo tempo, necessitando-se normalmente de 4 a 5 dias para a confirmação dos resultados $[4,6]$. Portanto, o emprego de métodos rápidos, simples e confiáveis, é importante tanto no diagnóstico de toxinfecção, como também, e principalmente, no controle de qualidade de alimentos.

Diversas técnicas imunológicas já foram desenvolvidas, usando tanto anticorpos monoclonais como policlonais os quais detectam a maioria dos sorotipos de Salmonella associados à infecção humana $[12,18,21$, 25, 33, 40]. Estes ensaios estão disponiveis comercial-

1. Recebido para publicação em 21/05/2002. Aceito para publicação em 25/02/2003 (000828).

2 Universidade Estadual de Londrina, Centro de Ciências Agrárias, Departamento de Tecnologia de Alimentos e Medicamentos, Campus Universitário, C.P. 6001, CEP:87051-970, Londrina, PR, Brasil, e-mail: tereza@uel.br

* A quem a correspondência deve ser enviada. mente na forma de kits [3], geralmente de custo inacessivel para a maioria dos laboratórios brasileiros, principalmente para aqueles públicos e oficiais de diagnóstico de toxinfecção alimentar.

O objetivo deste trabalho foi a produção de reagentes imunológicos para a detecção direta de Salmonella Enteritidis em alimentos, empregando-os na padronização de um ensaio imunoenzimático - ELISA sanduíche.

\section{2 - MATERIAL E MÉTODOS}

\section{1 - Produção e purificação do anti-soro}

O anti-soro policlonal para Salmonella Enteritidis foi obtido no Laboratório de Ciência de Alimentos, Departamento de Tecnologia de Alimentos e Medicamentos (TAM), Centro de Ciências Agrárias da Universidade Estadual de Londrina. O anti-soro foi produzido em coelho branco Nova Zelândia utilizando-se flagelina purificada gentilmente doada pelo Dr. Gary Wyatt do "Institute of Food Research", Norwich, Inglaterra. Na primeira dose foram inoculadas $100 \mu \mathrm{g}$ de flagelina e após 9 dias foi injetada a mesma quantidade de antígeno. Após 70 dias, foi inoculada uma dose de reforço com $300 \mu \mathrm{g}$ de flagelina. As doses de flagelina foram administradas por injeção subcutânea, distribuídas em três diferentes locais na região dorsal do animal. O adjuvante de Freund completo foi empregado na primeira dose e o incompleto na segunda e terceira doses. 
O anti-soro imune foi obtido por sangria da veia marginal da orelha ou por punção cardiaca. Após uma semana da terceira dose, oito coletas foram realizadas semanalmente durante dois meses.

$\mathrm{O}$ anti-soro foi purificado por cromatografia de afinidade com Sepharose Proteína A (Pharmacia) de acordo com ALCOCER [1]. Aliquotas de 10mL do anti-soro foram colocadas na coluna que foi lavada três vezes com tampão fosfato de sódio (PBS) 0,1M pH 7,4. A fração contendo IgG anti-flagelina foi eluída a $4{ }^{\circ} \mathrm{C}$ com tampão citrato de sódio $0,05 \mathrm{M} \mathrm{pH} \mathrm{2,8,} \mathrm{corrigindo-se} \mathrm{imediatamente} \mathrm{o} \mathrm{pH}$ do eluído com tampão TRIS $1 \mathrm{M}$ pH 8,8. As frações lidas a $280 \mathrm{~nm}$, contendo as maiores concentrações protéicas, foram misturadas e dialisadas em PBS, sendo o teor de proteina determinado pelo método de LOWRY et al. [30]. $\mathrm{O}$ anti-soro purificado foi analisado por eletroforese em gel de poliacrilamida, conforme o descrito por ITANO [27].

\section{2 - Preparação da suspensão de Salmonella Enteritidis}

Suspensões bacterianas de Salmonella Enteritidis (doação da Dra. Halha Ostrensky Saridakis, Universidade Estadual de Londrina, PR, Brasil), foram preparadas de acordo com o preconizado por WYATT et al. [38], com algumas modificações [1]. Para uso no imunoensaio, as células bacterianas foram cultivadas em BHI e mortas pelo calor empregando-se banho-maria a $72^{\circ} \mathrm{C}$ durante $15 \mathrm{mi}-$ nutos. Após este tratamento térmico, as células foram centrifugadas a $650 \mathrm{xg}$ por 15 minutos, lavadas três vezes com salina estéril ( $\mathrm{NaCl} 8,5 \mathrm{~g} / \mathrm{L})$ e suspendidas novamente em salina para ajustar a absorbância de 0,6 a 650nm.

\section{3 - Avaliação da especificidade do anti-soro produzido}

Para a avaliação das reações cruzadas, empregouse a metodologia descrita por LEE et al. [29], com modificações de ALCOCER [1]. Utilizaram-se suspensões de Salmonella Enteritidis (doação da Dra. Halha Ostrensky Saridakis, Universidade Estadual de Londrina, PR, Brasi1), Salmonella Infantis, Salmonella Newport, Salmonella Typhimurium (sorotipos obtidos no Instituto Adolfo Lutz, São Paulo, SP, Brasil), Citrobacter freundii, Enterobacter aerogenes, Enterobacter cloacae, Escherichia coli, Klebsiella pneumoniae, Morganella morganii e Proteus mirabilis (doados pelo Prof. Francisco Herrero, Universidade Estadual de Maringá, PR, Brasil).

Neste ensaio foram usadas microplacas de poliestireno (NUNC-PolySorp) revestidas com $100 \mathrm{~mL}$ das suspensões bacterianas. O soro policlonal anti-flagelina foi diluído a $1: 100 ; 1: 1000 ; 1: 10.000 ; 1: 100.000 \mathrm{e}$ 1:1.000.000 em tampão fosfato de sódio 0,15M pH 7,4 contendo 0,05\% de Tween 20 (PBST 0,05\%). Anti-IgG de coelho ligado à fosfatase (SIGMA Immuno Chemical A - 3687) diluído a 1:1000 em PBST 0,05\% foi empregado como conjugado e p-nitrofenil fosfato (SIGMA 104-105) como substrato. A absorbância foi lida a $405 \mathrm{~nm}$ em espectrofotômetro leitor de microplacas Emax S/N E9637.

Como recomendado por LEE et al. [29], para o cálculo da porcentagem de reação cruzada com cada microrganismo testado foi utilizada a diluição do anticorpo correspondente à metade da absorbância obtida com a suspensão de Salmonella Enteritidis. Esse valor foi dividido pela diluição do anticorpo obtido com cada uma das suspensões de enterobactérias e dos outros sorotipos de Salmonella testados. Os testes foram realizados três vezes em triplicata Curvas de regressão linear realizadas no programa MicroCal Origen 3.01 da MicroCal Software foram empregadas no cálculo das porcentagens de reação cruzada e exemplificada a seguir para Salmonella Typhimurium:

Fórmula das curvas de regressão linear $\mathrm{Y}=\mathrm{a}+\mathrm{bx}$

Salmonella Enteritidis $\quad \mathrm{Y}=0,26382+1754,93205 \mathrm{x}_{1}$

Salmonella Typhimurium $\quad \mathrm{Y}=0,10884+339,90192 \mathrm{x}_{2}$

$\mathrm{Y}=1,0095$ (metade da absorbância máxima de 2,019 para Salmonella Enteritidis)

$\%$ de reação cruzada $=\mathrm{x}_{1} / \mathrm{x}_{2} \times 100$

16,03\% de reação cruzada de Salmonella Typhimurium

\section{4 - Preparo do conjugado anti-flagelina peroxidase}

O conjugado anti-flagelina peroxidase foi preparado segundo a técnica proposta por WILSON, NAKANE [36], com modificações [37]. Foram dissolvidas $4 \mathrm{mg}$ de peroxidase (SIGMA Immuno Chemical A - 0545) em $1 \mathrm{~mL}$ de água destilada e imediatamente adicionados $0,2 \mathrm{~mL}$ de periodato de sódio $\left(\mathrm{NaIO}_{4}\right) \mathrm{O}, 1 \mathrm{M}$ recém-preparado. A mistura foi agitada a temperatura ambiente por $20 \mathrm{mi}-$ nutos e dialisada "overnight" com $500 \mathrm{~mL}$ de tampão acetato $1 \mathrm{mM} \mathrm{pH} 4,4$ a $4^{\circ} \mathrm{C}$.

Após a diálise, o pH foi ajustado para 9,0 a 9,5 com $20 \mu \mathrm{L}$ de tampão carbonato de sódio 0,2M pH 9,5. Imediatamente foram adicionados $8 \mathrm{mg}$ de IgG anti-flagelina, purificada conforme item 2.1 , dissolvida em $1 \mathrm{~mL}$ de tampão carbonato de sódio $0,01 \mathrm{M}$ pH 9,5. Após agitação da mistura reativa por duas horas em temperatura ambiente, foi adicionado $0,1 \mathrm{~mL}$ de boridrato de sódio $\left(\mathrm{NaBH}_{4}\right)$ $4 \mathrm{mg} / \mathrm{mL}$ recém-preparado. A mistura foi mantida a $4^{\circ} \mathrm{C}$ por duas horas, dialisada "overnight" com tampão fosfato de sódio (PBS) $0,01 \mathrm{M} \mathrm{pH} \mathrm{7,4} \mathrm{a} 4^{\circ} \mathrm{C}$ e clarificada por centrifugação. Para cada $1 \mathrm{mg}$ de conjugado foram adicionadas $10 \mathrm{mg}$ de soro albumina bovina por mililitro de água destilada. O conjugado preparado foi dividido em aliquotas de $0,1 \mathrm{~mL}$ conservado a $4^{\circ} \mathrm{C}$ para uso e a $-70^{\circ} \mathrm{C}$ para maior tempo de estocagem.

\section{5 - Determinação do título do conjugado anti- flagelina peroxidase e padronização do ELISA}

O título do conjugado foi determinado baseando-se no método preconizado por FEY, PFISTER \& RUEGG [15], com algumas modificações. 
Microplacas de poliestireno NUNC MaxiSorp foram revestidas com $300 \mu \mathrm{L}$ de uma solução de IgG antiflagelina purificada (item 2.1) e diluída em tampão carbonato bicarbonato de sódio 0,05M pH 9,6 (tampão de cobertura) na concentração de $10 \mu g$ de IgG/mL. Após 18 horas de incubação a $4^{\circ} \mathrm{C}$, as microplacas foram lavadas por três vezes com água purificada e adicionadas de $200 \mu \mathrm{L}$ de leite desnatado (Molico-NESTLE) 5\% em tampão carbonato bicarbonato de sódio 0,05M pH 9,6. Após incubação por 1 hora a $37^{\circ} \mathrm{C}$, as microplacas foram lavadas três vezes com PBS contendo $0,05 \%$ de Tween (PBST 0,05\%) e mantidas a $-20^{\circ} \mathrm{C}$. Para o uso as microplacas foram colocadas na estufa a $35^{\circ} \mathrm{C}$ por 10 minutos. A seguir, $100 \mu \mathrm{L}$ de suspensão de Salmonella Enteritidis com absorbância de 0,6, preparada conforme item 2.2, foram adicionados em cada orificio e as microplacas incubadas por 2 horas a $37^{\circ} \mathrm{C}$. Após cinco lavagens com PBST 0,05\%, foram adicionados, em triplicata, $100 \mu \mathrm{L}$ do conjugado anti-flagelina peroxidase, preparado conforme item 2.4, diluido a 1:500; 1:1000; 1:1500; 1:2000; 1:2500; e 1:3000 em PBST 0,05\% e as microplacas incubadas a $37^{\circ} \mathrm{C}$ por uma hora. Após cinco lavagens com PBST 0,05\%, foram adicionados $100 \mu \mathrm{L}$ de 3, 3', 5, 5' tetrametil benzidina (TMB) (SIGMA T-8665). A reação enzimática foi interrompida após 10 minutos com $50 \mu \mathrm{L}$ de $\mathrm{H}_{2} \mathrm{SO}_{4} 2 \mathrm{M}$ e a absorbância lida a 450nm.

O título do conjugado peroxidase anti-flagelina foi a diluição cuja absorbância obtida a 450nm foi de 0,5 a 1,0 , após 10 minutos de reação com o substrato.

Após a determinação do título do conjugado e com a finalidade de melhorar a eficiência do ensaio, o procedimento descrito acima foi repetido utilizando-se $20 \mathrm{mi}-$ nutos de reação com o substrato e volumes de 50 e $200 \mu \mathrm{L}$ da suspensão de Salmonella Enteritidis com absorbância 0,6. Ensaio foi realizado três vezes em triplicata.

\section{6 - Tempo de validade do conjugado anti-flagelina peroxidase}

Testes semanais, utilizando a metodologia descrita no item 2.5, foram realizados durante dois meses com o conjugado conservado a $4^{\circ} \mathrm{C}$ e diluído a 1:500.

\section{7 - Avaliação da sensibilidade do ELISA padronizado}

Para avaliar a sensibilidade do ELISA, foram preparadas suspensões de $10^{1}$ a $10^{6}$ células de Salmonella Enteritidis por mililitro de PBST 0,05\% estéril. As diluições foram feitas a partir de crescimento em BHI, incubado por 24 horas a $37^{\circ} \mathrm{C}$. A confirmação do número de células foi realizada através da contagem de colônias no meio de Hektoen. As suspensões sofreram tratamento térmico prévio, conforme item 2.2, antes da execução do ELISA padronizado conforme item 2.5.

\section{8 - Aplicação do ensaio imunoenzimático - ELISA padronizado em extrato alimentar}

A emulsão para maionese caseira foi preparada em liquidificador com dois ovos inteiros e $10 \mathrm{~mL}$ de suco de limão, que foi adicionada de 300 gramas de batatas co- zidas e 150 gramas de cenouras cozidas e cortadas em cubos. O pH foi em torno de 4,5.

Vinte e cinco gramas desta maionese foram assepticamente pesados e contaminados com Salmonella Enteritidis cultivada em infusão de cérebro e coração (BHI) a $37^{\circ} \mathrm{C}$ por 24 horas. Foram inoculadas $1,10,100$ e 1000 células por cada $25 \mathrm{~g}$ de alimento, em duplicata com duas repetições em dias diferentes. A confirmação do inóculo adicionado foi realizada através de cultura da maionese contaminada em Hektoen. Uma amostra de maionese não contaminada foi empregada como controle negativo do ensaio.

Para o pré-enriquecimento, amostras contaminadas foram homogeneizadas em Stomacher (Seward Stomacher 400 Lab System) por 1 minuto com $225 \mathrm{~mL}$ de água peptonada tamponada e incubadas a $37^{\circ} \mathrm{C}$. Após 24 horas de incubação, foram transferidas aliquotas de $0,1 \mathrm{~mL}$ para $9,9 \mathrm{~mL}$ de Rappaport Vassiliadis (RV) e o enriquecimento seletivo realizado a $42^{\circ} \mathrm{C}$ por $24 \mathrm{~h}$.

Para a realização do ELISA, após o pré-enriquecimento e enriquecimento seletivo, as amostras de maionese foram centrifugadas a $650 \mathrm{x} \mathrm{g}$ por $30 \mathrm{~min}$, os sobrenadantes separados e aquecidos a $72^{\circ} \mathrm{C}$ por $15 \mathrm{~min}$.

\begin{tabular}{|c|}
\hline $\begin{array}{c}\text { COBERTURA } \\
300 \mu \mathrm{L} \text { de } 10 \mu \mathrm{g} \text { de IgG anti-flagelina pura }\end{array}$ \\
\hline $\begin{array}{c}\Downarrow 18 \text { horas a } 4^{\circ} \mathrm{C} \\
\text { lavagem } 3 \text { vezes com água }\end{array}$ \\
\hline $\begin{array}{l}\text { BLOQUEIO } \\
200 \mu \mathrm{L} \text { com leite desnatado } 5 \% \text { em tampão } \\
\text { cobertura }\end{array}$ \\
\hline $\begin{array}{c}\Downarrow 1 \text { hora a } 37^{\circ} \mathrm{C} \\
\text { lavagem } 3 \text { vezes com PBST 0,05\% }\end{array}$ \\
\hline $\begin{array}{c}\text { SUSPENSÃO } \\
50 \mu \mathrm{L} \text { de de Salmonella Enteritidis } \\
\text { DO 0,6 a 650nm }\end{array}$ \\
\hline $\begin{array}{c}\Downarrow 2 \text { horas a } 37^{\circ} \mathrm{C} \\
\text { lavagem } 5 \text { vezes com PBST 0,05\% }\end{array}$ \\
\hline $\begin{array}{c}\text { CONJUGADO } \\
\text { 100 } \mu \mathrm{L} \text { peroxidase anti-flagelina para } \\
\text { Salmonella Enteritidis diluído } 1: 500\end{array}$ \\
\hline $\begin{array}{c}\Downarrow 1 \text { hora a } 37^{\circ} \mathrm{C} \\
\text { lavagem } 5 \text { vezes com PBST 0,05\% }\end{array}$ \\
\hline $\begin{array}{c}\text { SUBSTRATO } \\
\text { 100 } \mu \text { L de TMB }\end{array}$ \\
\hline$\Downarrow 10$ minutos \\
\hline $50 \mu \mathrm{L}$ de $\mathrm{H}_{2} \mathrm{SO}_{4}$ \\
\hline$\Downarrow$ \\
\hline LEITURA a 450nm \\
\hline
\end{tabular}

FIGURA 1. Protocolo de padronização de ELISA

Microplacas de poliestireno (NUNC MaxiSorp) revestidas com anti-flagelina, conforme item 2.5 , foram adicionadas de $50 \mu \mathrm{L}$ da suspensão de Salmonella Enteritidis com absorbância de 0,6 (utilizada como controle positivo), sobrenadante da maionese não contaminada (utilizada como controle negativo) e os sobrenadantes da maionese contaminada incubados a $37^{\circ} \mathrm{C}$ e $42^{\circ} \mathrm{C}$ por 8 e $24 \mathrm{~h}$ em água peptonada tamponada 
e RV, respectivamente. O restante do procedimento foi realizado conforme item 2.5 empregando-se $100 \mu \mathrm{L}$ do conjugado diluído a 1:500 e leitura de absorbância após 10 minutos de reação com o TMB (Figura 1).

Paralelamente, contagens de colônias em Hektoen foram realizadas a partir de aliquotas retiradas da água peptonada tamponada e RV, após 8 e 24 horas de incubação a $37^{\circ} \mathrm{C}$ e $42^{\circ} \mathrm{C}$, respectivamente.

\section{3 - RESULTADOS E DISCUSSÃO}

\section{1 - Especificidade do soro anti-flagelina para Salmonella Enteritidis}

As curvas de regressão linear usadas no cálculo das reações cruzadas se encontram na Figura 2. O antisoro apresentou pouca reação cruzada com os sorotipos Typhimurium, Infantis e Newport, sendo que as porcentagens foram de 16,0; 11,9 e 6,4\%, respectivamente ( $\mathrm{Ta}$ bela 1). Essas porcentagens de reação cruzada foram, em geral, menores que aquelas encontradas por LEE et al. [29], que padronizaram ELISA sanduiche para detecção de Salmonella Typhimurium em alimentos empregando flagelina como antigeno. Esses autores obtiveram anti-soro com porcentagens de reação cruzada de $32 \%$ para Salmonella Hadar, de 30\% para Salmonella Weltevreden, de 20\% para Salmonella Agona e de $10 \%$ para Salmonella Enteritidis.

A flagelina tem sido reportada como um dos melhores antígenos para a produção de anti-soro tanto para triagem sorológica como para padronização de ensaios imunoenzimáticos de salmonellas móveis. Assim, IBRAHIM, LYONS [26] encontraram bons resultados quando padronizaram ensaios para a detecção de Salmonella em alimentos empregando flagelina.

Menor especificidade tem sido encontrada quando são produzidos anticorpos para lipopolissacarídeo (LPS) ou fimbrias. BAAY, HUIS \& VELD [5] observaram reações cruzadas com vários sorotipos de Salmonella quando LPS foi empregado no preparo do anti-soro, o mesmo não ocorrendo com anti-soro preparado utilizando antígenos flagelares. Resultados semelhantes foram encontrados por HASSAN et al. [22] e TIMONEY et al. [35], que também empregaram antigenos flagelares.

Assim sendo, baseado nestes fatos e analisando os resultados obtidos neste trabalho pode-se sugerir a utilização da flagelina para a produção de anti-soro, principalmente, se os anticorpos forem policlonais. Por outro lado, REIS, MAMIZUKA \& FRANCO [33] produziram anticorpos policlonais especificos empregando culturas formolizadas de Salmonella Typhimurium, Agona, Anatum e Oranienburg e encontraram que o soro monovalente não absorvido (contendo as aglutininas f, $\mathrm{g}, \mathrm{s})$ e o "pool" de antisoros absorvidos detectaram todos os sorotipos de Salmonella testados. O soro polivalente não absorvido revelou resultados falso-positivos com $C$. freundii, $P$. alcalifaciens e $P$. mirabilis, que foram eliminados com a absorção. Portanto, a absorção do antisoro para Salmonella Enteritidis produzido neste traba- lho poderia diminuir ou eliminar as reações cruzadas observadas (Tabela 1), principalmente, com outros sorotipos de Salmonella.
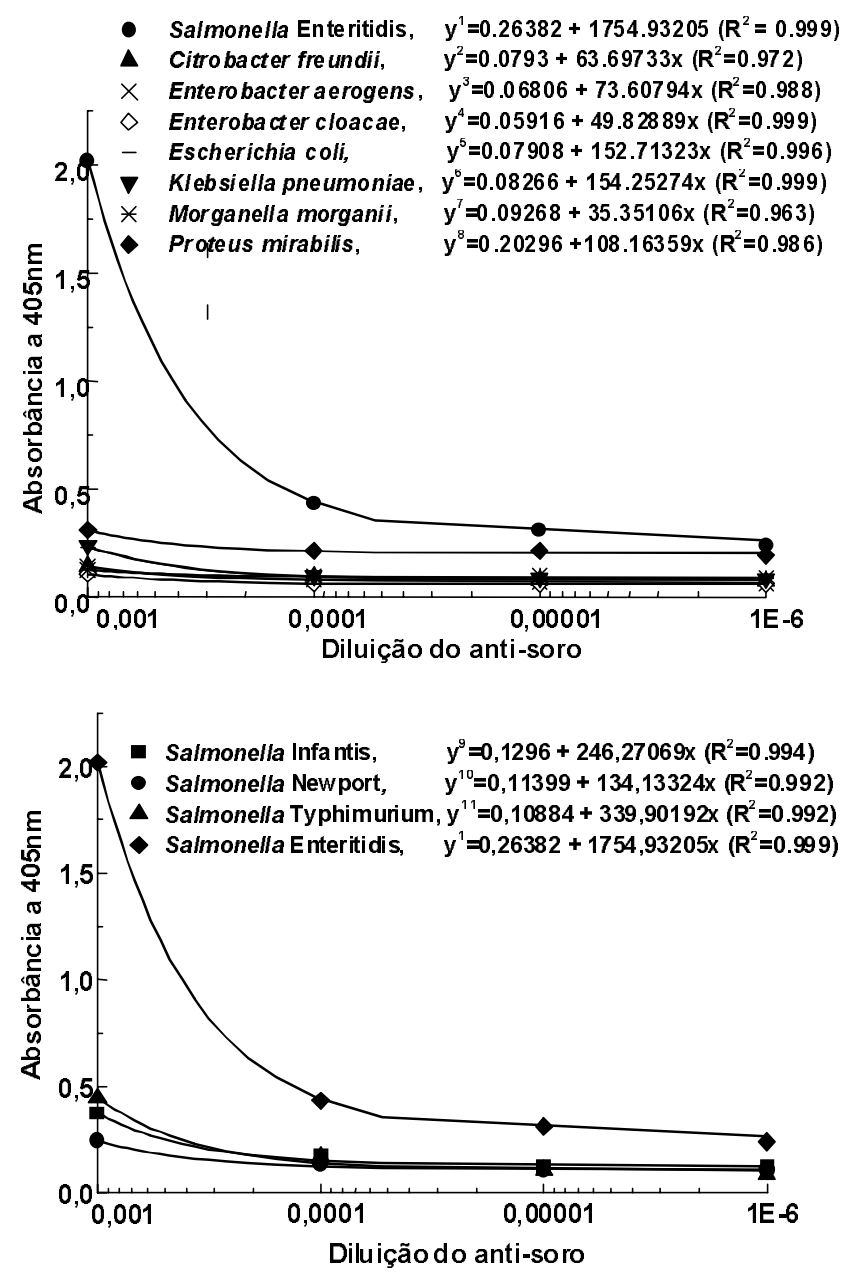

FIGURA 2. Curvas de diluição do soro anti-flagelina empregadas no cálculo das reações cruzadas

TABELA 1. Porcentagem de reação do anticorpo policlonal anti-flagelina com Salmonella Enteritidis e com outras enterobactérias

Enterobactérias Porcentagem Reação

Citrobacter freundii 2,9

Enterobacter aerogens 3,3

Enterobacter cloacae 2,2

Escherichia coli 7,0

Klebsiella pneumoniae

Morganella morganii

7,1

Proteus mirabilis

1,6

Salmonella Infantis

5,7

Salmonella Newport

11,9

Salmonella Typhimu

6,4

Salmonella Enteritidis 100,0 


\section{2 - Determinação do título e estabilidade do con- jugado peroxidase}

O título do conjugado peroxidase, após a análise da Figura 3, foi de 1:500 sendo a média de absorbância a 450 nm de 0,874 . Os valores de absorbância para os controles negativos variaram de 0,115 a 0,226 (Figura 3).

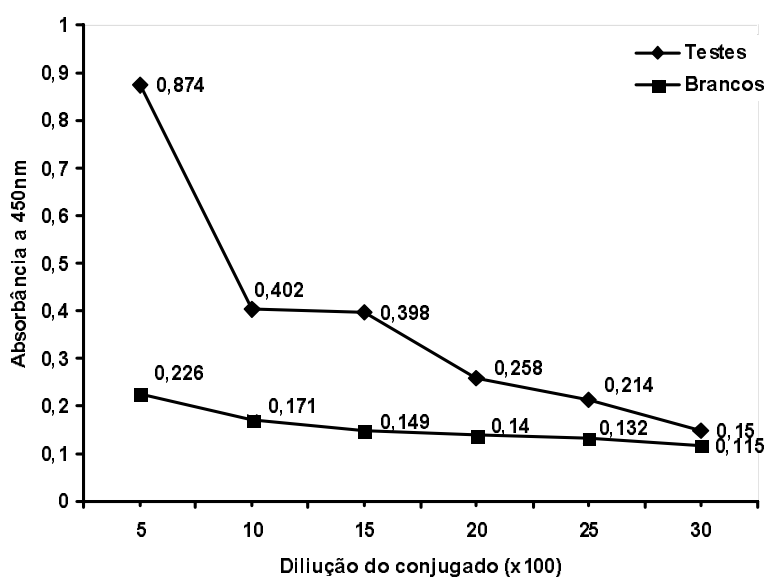

FIGURA 3. Título do conjugado anti-flagelina peroxidase para Salmonella Enteritidis determinado por ELISA sanduíche

O conjugado peroxidase, descongelado para o uso, foi conservado a $4^{\circ} \mathrm{C}$ e o estudo da estabilidade realizado através de análises semanais. No decorrer de dois meses houve perda gradativa de aproximadamente 0,1 na absorbância, prejudicando a sensibilidade do ensaio. Portanto, dois meses foi o tempo máximo de estabilidade do conjugado peroxidase, mantido a $4^{\circ} \mathrm{C}$.

OLIVEIRA [32] observou que o conjugado antienterotoxina estafilocócica A peroxidase conservado a $-70^{\circ} \mathrm{C}$ manteve a atividade inalterada por um ano. Porém, uma vez descongelado e mantido a $4^{\circ} \mathrm{C}$ o tempo de uso foi de dois meses, como o observado no presente trabalho. WILSON, NAKANE [36] chegaram a mesma conclusão sobre conjugado preparado com peroxidase conservado a $-70^{\circ} \mathrm{C}$, que manteve atividade de pelo menos 2 anos quando freqüentes congelamentos e descongelamentos foram evitados.

\section{3 - Determinação da sensibilidade do método ELISA padronizado na detecção de Salmonella Enteritidis}

Para a padronização do ELISA sanduíche foram testados dois tempos diferentes de reação com o substrato e três volumes diferentes de suspensão de Salmonella (item 2.5). Os melhores resultados foram obtidos com $50 \mu \mathrm{L}$ de suspensão de Salmonella Enteritidis D.0. 0.6 a 650nm e 10 minutos de reação com o TMB.

A sensibilidade do ELISA foi de $10^{4}$ células / $\mathrm{mL}$, igual à obtida por BRIGMON, ZAM \& WILSON [9], que padronizaram um ensaio imunoenzimático empregando anticorpos monoclonais e policlonais. A mesma sensibilidade também foi encontrada por HOLT, GAST \& GREENE [23] utilizando somente anticorpos monoclonais para flagelina de Salmonella.
REIS, MAMIZUKA \& FRANCO, [33] encontraram sensibilidade de $10^{3} \mathrm{UFC} / \mathrm{mL}$ em cultura pura ao utilizarem anti-soros policlonais produzidos com culturas formolizadas de quatro sorotipos de Salmonella.

BRIGMON et al. [8] ao padronizarem um ELISA empregando anticorpo monoclonal de classe IgG específico para lipopolissacarídeos de Salmonella Enteritidis (ASCII) obtiveram sensibilidade de $10^{5}$ células $/ \mathrm{mL}$ em cultivo puro.

A produção de anticorpos policlonais apresenta algumas limitações tais como, necessidade do fornecimento contínuo de antígeno purificado para as injeções, manutenção em laboratório de animais, variação do soro dependendo do tempo de imunização e da intensidade da resposta imune, variabilidade individual entre os animais ou mesmo no próprio animal de uma sangria para outra [19].

Apesar das desvantagens dos anticorpos policlonais, no presente trabalho foi padronizado um ensaio que permitiu a detecção de Salmonella Enteritidis com limite de detecção de $10^{4}$ células / mL de cultivo puro.

Anticorpos monoclonais oferecem várias vantagens, como uniformidade, especificidade, homogeneidade e afinidade para um simples epitopo [19]. Entretanto, melhores condições de infra-estrutura são necessárias para o trabalho com a tecnologia de hibridomas. Assim sendo, anticorpos monoclonais poderão ser produzidos no futuro, visando aumentar a especificidade e a sensibilidade do ensaio padronizado neste trabalho.

\section{4 - Aplicação do ELISA padronizado em extratos alimentares}

Amostras de maionese de batata e cenoura, contaminadas com 1, 10, 100 e 1000 células de Salmonella Enteritidis/25g foram analisadas pelo ELISA sanduiche padronizado (item 3.3). Com este ensaio foi possivel detectar 1 célula de Salmonella Enteritidis em $25 \mathrm{~g}$ de alimento, após enriquecimento em água peptonada alcalina por 24 horas a $37^{\circ} \mathrm{C}$ (Figura 4).

Na Figura 4 podemos observar que, após 8 e 24 horas de incubação em água peptonada, as absorbâncias foram proporcionais ao inóculo inicial, ou seja, quanto menor o inóculo menor a absorbância obtida. Após o enriquecimento seletivo em RV por 8 e 24 horas de incubação, todas as amostras contaminadas com Salmonella foram detectadas pelo ELISA padronizado.

A Legislação Brasileira exige para consumo humano a ausência de Salmonella em $25 \mathrm{~g}$ de alimentos [7]. Portanto, o ensaio precisa detectar 1 célula em $25 \mathrm{~g}$ de amostra. O método tradicional oferece essa sensibilidade após 24 horas de pré-enriquecimento e 24 horas de enriquecimento seletivo.

O ELISA desenvolvido neste trabalho apresentou sensibilidade de $10^{4}$ células / $\mathrm{mL}$ em cultivo puro. Quando o ensaio foi realizado com maionese de batata e cenoura, a sensibilidade foi de $10^{5}$ células/g, com inóculo inicial de 10 células e período de incubação de 8 horas em água peptonada. Quando a contaminação foi com 1 célula em 
25g de maionese foi possivel detectar Salmonella após 24 horas de incubação em água peptonada.

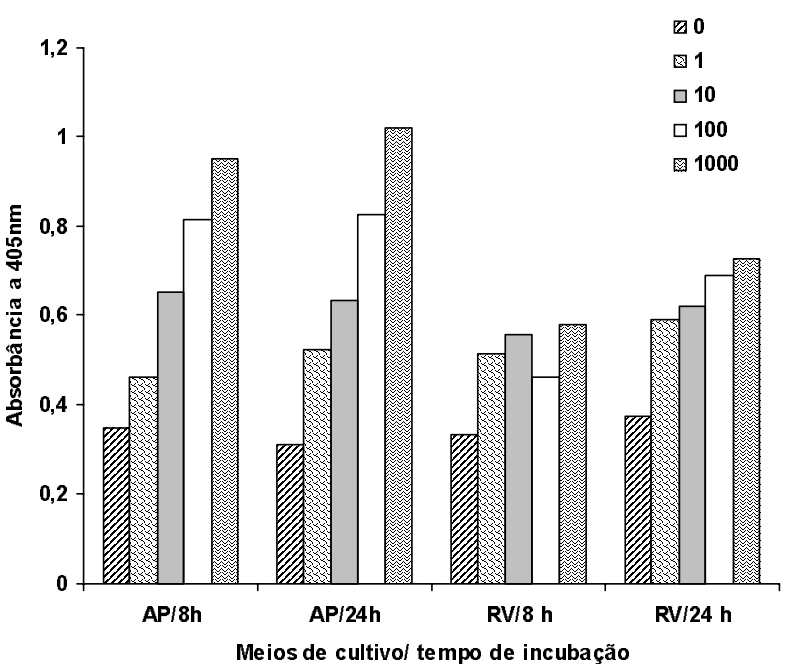

FIGURA 4. Avaliação da sensibilidade do ELISA em maionese contaminada com 1, 10, 100 e 1000 UFC de Salmonella Enteritidis/25g, após incubação por 8 e 24 horas em água peptonada tamponada (AP) e Rappaport-Vassiliadis (RV).

BRIGMON, ZAM \& WILSON [9] comprovaram que a sensibilidade do ELISA, desenvolvido com anticorpos monoclonais e policlonais para detectar Salmonella em alimentos, pode variar dependendo do tipo de amostra. Esses autores analisaram carne de frango, pele de frango e ovo. Salmonella Enteritidis foi detectada em uma concentração de $10^{4}$ células $/ \mathrm{mL}$ em cultivo puro e na carne de frango. A sensibilidade decresceu para $10^{5} \mathrm{e}$ $10^{7}$ quando pele de frango e ovos foram analisados, respectivamente. A possivel explicação para essas diferenças pode ser a presença de interferentes do alimento como albumina no ovo e gordura na pele, que atuariam como agentes bloqueadores, inibindo a ligação do anticorpo.

Portanto, o método padronizado neste trabalho precisa ser validado através da análise de outros alimentos com a finalidade de observar a interferência de outras matrizes alimentares.

É complexo analisar os diferentes ensaios imunoenzimáticos empregados na detecção de Salmonella não somente pelo tipo de alimento que afeta a performance do ensaio, como também, os variados protocolos de enriquecimento que são usados. Para a obtenção de sensibilidade equivalente ao método tradicional (1 célula/25g), os métodos imunoenzimáticos, necessitam de um, dois ou três passos prévios de incubação e vários autores indicam o uso de diferentes meios de pré-enriquecimento e de enriquecimento seletivo [3, 19, 24, 28, 39].

A maioria dos kits inclui três passos sucessivos de preparo da amostra antes da análise pelo ELISA [4]. Normalmente, o processo inicia com uma incubação de 18-24 horas em água peptonada tamponada, seguido de uma segunda incubação por 18-24 horas em meios de enriquecimento seletivo e pós-enriquecimento em cal- do $M$ por 6 horas [2, 4].

O caldo selenito cistina, caldo Rappaport Vassiliadis e/ou caldo tetrationato são os meios de enriquecimento seletivo mais utilizados. A eficácia do caldo RappaportVassiliadis, do caldo tetrationato e do caldo selenito cistina para recuperar Salmonella spp. de alimentos, quando o número de células é pequeno, foi avaliada por HAMMACK et al. [20]. Esses autores concluíram que é recomendável usar tanto caldo tetrationato quanto Rappaport-Vassiliadis para recuperar Salmonella spp. de qualquer tipo de alimento.

MANTTINGY, GEHLE [31] usaram meio de pré-enriquecimento em tampão fosfato e pós-enriquecimento em caldo M para detectar 1 célula de Salmonella em $25 \mathrm{~g}$ de alimento. IBRAHIM, LYONS [26] usaram 24 horas de préenriquecimento em água peptonada tamponada seguido de 18 - 24 horas de enriquecimento seletivo em caldo manitol selenito cistina, para obter a mesma sensibilidade do método tradicional. Esses autores não utilizaram pós-enriquecimento em caldo $\mathrm{M}$ porque este meio nem sempre oferece condições para o adequado crescimento de Salmonella, o que também foi observado por FLOWERS [17]. Devido a esta incerteza e com a finalidade de obter um ensaio mais rápido e econômico, no presente trabalho não foi utilizado o caldo $\mathrm{M}$ como meio de pós-enriquecimento. A não utilização deste meio não comprometeu a detecção de 1UFC de Salmonella Enteritidis em $25 \mathrm{~g}$ de maionese.

ARBAULT, POUMEROL [2] desenvolveram um ELISA para detecção de Salmonella com dois passos de enriquecimento, utilizando anticorpos anti-flagelina. Foram necessárias 16 a 20 horas de incubação em água peptonada tamponada e 18 a 24 horas de enriquecimento seletivo em caldo Rappaport Vassiliadis-Soja. Os limites de detecção encontrados foram de 3UFC/25g e 98\% de correlação com o método padrão ISO n. 6579.

LEE et al. [29] desenvolveram um ELISA para detectar SalmonellaTyphimurium em alimentos usando o meio SCDM como único meio de enriquecimento e encontraram que é possivel detectar, em chocolate, 10 células/ 25g. O ELISA padronizado neste trabalho apresentou sensibilidade maior que a encontrada por LEE et al. [29] e ARBAULT, POUMEROL [2], detectando 1 célula/25g com uma única etapa de pré-enriquecimento, indicando que a sensibilidade do método é adequada.

TIAN et al. [34] descreveram a detecção de Salmonella spp. por ELISA sanduíche usando caldo manitol para enterobactérias (EEM) e caldo ácido-brilhante verdenovobiocina cloridepiridinisulfônico (DMPBN). Os tempos de incubação a $42^{\circ} \mathrm{C}$ foram de 6 horas para o EEM e de 27 horas para o DMPBN. Entretanto, nesse método o antígeno utilizado para a imunização dos animais não foi a flagelina e sim a dulcitol 1-fosfato desidrogenase, enzima que fermenta o dulcitol e é uma característica metabólica do subgênero Salmonella I.

Vários ensaios imunoenzimáticos para detecção de Salmonella spp. em alimentos já foram reportados [2, 3, $6,9,13,16,19,26,29,31,33,37,38]$. Além disso, 
vários métodos ELISA estão disponiveis comercialmente na forma de kits $[3,14]$. Porém, o custo é muito elevado para a maioria dos laboratórios brasileiros, principalmente para aqueles oficiais de diagnóstico de toxinfecção alimentar. Assim sendo, o ensaio desenvolvido neste trabalho, após ser validado, poderá ser utilizado por laboratórios com recursos limitados para a compra de kits rápidos de detecção de patógenos.

\section{4 - CONCLUSÕES}

- A avaliação das reações cruzadas mostrou que o anti-soro tem pouca reação cruzada com os sorotipos Typhimurium, Infantis e Newport, como também, com outras enterobactérias testadas.

- O conjugado peroxidase manteve-se estável durante dois meses a $4^{\circ} \mathrm{C}$ e o seu uso deve ser exclusivamente durante este tempo.

- A sensibilidade do ensaio em microplacas com conjugado peroxidase obtido com anti-flagelina de Salmonella Enteritidis foi de $10^{4}$ células / $\mathrm{mL}$, quando testado em cultivo puro.

- O ensaio padronizado apresentou simplicidade e rapidez, com sensibilidade de 1 célula/25g de maionese de batata e cenoura, após 24 horas de incubação em água peptonada tamponada. Entretanto, é necessária a validação do método através da análise de diferentes alimentos contaminados natural e artificialmente com diferentes sorotipos de Salmonella.

\section{5 - REFERÊNCIAS BIBLIOGRÁFICAS}

[1] ALCOCER, I. Salmonella spp. : Padronização de ensaio imunoenzimático para detecção em alimentos. Londrina, 1999. 96p. Dissertação (Mestrado em Ciência de Alimentos) - Departamento de Tecnologia de Alimentos e Medicamentos, Centro de Ciências Agrárias, Universidade Estadual de Londrina (UEL).

[2] ARBAULT, P. ; POUMEROL, S. diffchamb.tech@wanadoo.fr. Salmonella detection in food: study of a two-step enrichment protocol combined with an ELISA. enviado no dia $12 / 09 / 99,12 \mathrm{~h} 40 \mathrm{~min}$. Mensagem para tereza@uel.br.

[3] ASSOCIATION OF OFFICIAL ANALYTICAL CHEMISTS - AOAC [on line] disponivel na internet via www uel: http:// www.aoac.org/testkits/microbiologykits.htm. Arquivo capturado em 6 de novembro de 2001.

[4] ASSOCIATION OF OFFICIAL ANALYTICAL CHEMISTS AOAC. Official Methods of Analysis of AOAC International. 16.ed. Virginia: AOAC, 1995. Cap. 17, p. 55-95.

[5] BAAY, M.F.D.; HUIS in't VELD, J.H.J. Alternative antigens reduce cross-reactions in an ELISA for the detection of Salmonella enteritids in poultry. Journal of Applied Bacteriology, n. 74, p. 243-247, 1993.

[6] BEUMER, R.R.; BRINKMAN, E.; ROMBOUTS, F.M. Enzymelinked immunoassays for the detection of Salmonella spp. : a comparison with other methods. International Journal of Food Microbiology, v. 12, p. 363-374, 1991.
[7] BRASIL. Ministério da Saúde. Resolução RDC n. 12, de 2 de janeiro de 2001. Regulamento Técnico sobre padrões microbiológicos para alimentos. Disponível na Internet via www uel: http://www.anvisa.gov. br/legis/resol/12_01rdc.htm. Acesso em 08 de janeiro de 2002.

[8] BRIGMON, R.L.; ZAM, S.G.; BITTON, G.; FARRAH, S.R. Detection of Salmonella Enteritidis in environmental samples by monoclonal antibody-based ELISA. Journal of Immunological Methods, v. 152, p. 135-142, 1992.

[9] BRIGMON, R.L.; ZAM, S.G.; WILSON, H.R. Detection of Salmonella enteritidis in eggs and chicken with enzymelinked immunosorbent assay. Poultry Science, v. 74, p. 1232-1236, 1995.

[10] CAMARGO, N. J.; SOUZA, I. L.; PUZYNA, I. P. ; PESTANA, A. Surtos de doenças transmitidas por alimentos em 1998. Curitiba: Secretaria de Saúde do Estado do Paraná, Centro de Saneamento e Vigilância Sanitária, 1999.

[11] CENTER FOR DISEASE CONTROL -CDC [on line] disponível na internet via www uel: http://www.cdc.gov/ncidod/ dbmd/diseaseinfo/salmonellosis-g.htm. Arquivo capturado em 11 de outubro de 2002.

[12] CHEN, S.; YEE, A.; GRIFFITHS, M.; WU, K.Y.; WANG, C.N ; RAHN, K.; DE GRANDIS, S.A. A rapid, sensitive and automated method for detection for Salmonella species in foods using AG-9600 amplisensor analyzer. Journal of Applied Microbiology, v. 83, p. 314-231, 1997.

[13] ENTIS, P. Validation of the ISO-GRID 2-day rapid screening method for detection of Salmonella spp. in egg products. Journal of Food Protection, v. 59, n. 5, p. 555-558, 1996.

[14] FENG, P. Commercial assay systems for detecting foodborne Salmonella: a review. Journal of Food Protection, v. 55, n. 11, p. 927-934, 1992.

[15] FEY, H.E.; PFISTER, H.; RUEGG, O. Comparative evaluation of different enzyme-linked immunosorbent assay systems for the detection of staphylococcal enterotoxins A, B e D. Journal of Clinical Microbiology, v. 19, p. 34-38, 1984.

[16] FLINT, S.H.; HARTLEY, N. J. Evaluation of the TECRA immunocapture ELISA for the detection of Salmonella typhimurium in foods. Letters in Applied Microbiology, v. 17, p. 4-6, 1993.

[17] FLOWERS, R.S. Comparison of rapid Salmonella screening methods and the conventional culture method. Food Technology, v. 39, n. 3, p. 103-108, 1985.

[18] FRANCO, B.D.G.M. Métodos alternativos de análise microbiológica: uma revisão. Bol SBCTA, v. 33, n. 2, p. 2292234, 1999.

[19] GAZZAZ, S.S.; RASCO, B.A.; DONG, F.M. Application of immunochemical assays to food analysis. Critical Reviews in Food Science and Nutrition, v. 32, n. 3, p. 197-229, 1992.

[20] HAMMACK, T.S.; AMAGUAÑA, R.M.; JUNE, G.A.; SHERROD, P. S.; ANDREWS, W.H. Relative effectiveness of selenite cystine broth, tetrathionate broth, and Rappaport-Vassiliadis medium for the recovery of Salmonella spp. from foods with a low microbial load. Journal of Food Protection, v. 62, n. 1, p. 16-21, 1999.

[21] HANAI, K.; SATAKE, M.; NAKANISHI, H.; VENKATESWARAN, K. Comparison of commercially available kits with standard methods for detection of Salmonella strains in foods. Applied and Environmental Microbiology, v. 63, n. 2, p. 775-778, 1997. 
[22] HASSAN, J.O.; BARROW, P. A.; MOCHETT, A.P. A.; McLEOD, S. Antibody response to experimental Salmonella typhimurium infection in chickens measured by ELISA. Veterinary Record, v. 126, n. 21, p. 519-522, 1990.

[23] HOLT, P. ; GAST, R.K.; GREENE, C.R. Rapid detection of Salmonella enteritidis in pooled liquid egg samples using a magnetic bead- ELISA system. Journal of Food Protection, v. 58, n. 9, p. 967-972, 1995.

[24] HONGSHENG, H.; GARCIA, M.M.; BROOKS, B.W.; NIELSEN, K.; SZE-PARK, N. G. Evaluation of culture enrichment procedures for use with Salmonella detection immunoassay. International Journal of Food Microbiology, v. 51, n. 2/3, p. 85-94, 1999.

[25] IBRAHIM, G.F.; FLEET, C.H.; LYONS, M.J.; WALKER, R.A. Immunological relationships between Salmonella flagelina and between these and flagellins from other species of Enterobacteriaceae. Medical Microbiology and Immunology, v. 174, p. 87-99, 1985.

[26] IBRAHIM, G.F.; LYONS, M.J. Detection of Salmonellae in foods with an enzyme immunometric assay. Journal of Food Protection, v. 50, n. 1, p. 59-61, 1987.

[27] ITANO, E. N. Formas moleculares de receptor para eritrócitos de carneiro em linfócito T, soro e saliva. São Paulo, 1989. 156p. Tese (Doutorado) - Escola Paulista de Medicina, São Paulo.

[28] JUNE, G.A.; SHERROD, P. S.; ANDREWS, W. Comparison of two enzyme immunoassay for recovery of Salmonella spp. from four low-moisture foods. Journal of Food Protection, v. 44, n. 8, p. 601-604, 1992.

[29] LEE, H.A.; WYATT, G.M.; BRAMHAM, S.; MORGAN, R. Enzyme-linked immunosorbent assay for Salmonella typhimurium in food: feasibility of 1-day Salmonella detection. Applied and Environmental Microbiology, v. 56, n. 6, p. 1541-1546, 1990.

[30] LOWRY, O. H.; ROSEBROUGH, N. J.; FARR, A. L.; RANDALL, R. J. Protein measurement with the folin phenol reagent. Journal of Biological Chemistry, n. 193, p. 265-275, 1951.

[31] MANTTINGY, J.A.; GEHLE, W.D. An improved enzyme immunoassay for the detection of Salmonella. Journal of Food Science, v. 49, p. 807-809, 1984

[32] OLIVEIRA, T.C.R.M. Produção de reagentes imunológicos para a detecção direta de enterotoxina estafilocócica A em alimentos. Londrina, 1994. 124p. Tese (Doutorado em Ciência de Alimentos) - Departamento de Ciência e Tecnologia de Alimentos, Centro de Ciências Agrárias, Universidade Estadual de Londrina (UEL).

[33] REIS, R.B.; MAMIZUKA, E.M.; FRANCO, B.D.G.M. Produção de imunorreagentes para uso em um teste imunoenzimático de detecção de Salmonella em alimen- tos. Ciênc. Tecnolog. Aliment., v. 21, n. 3, p. 261266, 2001

[34] TIAN, H.; MIYAMOTO, T.; OKABE, T.; KURAMITSU, Y.; HONJOH, K.; HATANO, S. Rapid detection of Salmonella spp. in foods by combination of a new selective enrichment and a sandwich ELISA using two monoclonal antibodies against dulcitol 1phosphate dehydrogenase. Journal of Food Protection, v. 59, n. 11, p. 1158-1163, 1996.

[35] TIMONEY, J.F.; SIKORA, N. ; SHIVAPRASAD, H.L.; OPITZ, M. Detection of antibody to Salmonella enteritidis by a $\mathrm{g}, \mathrm{m}$ flagellin-based ELISA. Veterinary Record, v. 127, n. 7, p. 168-169, 1990.

[36] WILSON, M.B.; NAKANE, P. K. Recent developments in the periodate method of conjugating horseradish peroxidase (HRPO) to antibodies. In: KNAPPP, W. K.; HOLUBAR, K.; WICK, G. (Ed). Immunofluorescence and related staining techniques. Amsterdam: North-Hollland Biomedical Press, 1978. p. 215-224.

[37] WYATT, G.M. Immunoassays for food poisoning bacteria and bacterial toxins. London: Chapman \& Hall, 1992. 129p.

[38] WYATT, G.M.; LANGLEY, M.N. ; LEE, H.A.; MORGAN, M.R.A. Further studies on the feasibility of one-day Salmonella detection by enzyme-linked immunosorbent assay. Applied and Environmental Microbiology, v. 59, n. 5, p. 1383-1390, 1993.

[39] WYATT, G.M.; LEE, H.A.; DIONYSIOU, S.; MORGAN, M.R.A.; STOKELY, D.J.; AL-HAJJI, A.H.; RICHARDS, J.; SILLIS, A.J.; JONES, P. H. Comparison of a microtitration plate ELISA with a standard cultural procedure for the detection of Salmonella spp. in chicken. Journal of Food Protection, v. 59, n. 3, p. 238-243, 1995.

[40] YOSHIMASU, M.A.; ZAWISTOWSKI, J. Application of rapid dot blot immunoassay for detection of Salmonella enterica serovar Enteritidis in eggs, poultry, and other foods. Applied and Environmental Microbiology, v. 67, n. 1, p. 459-461, 2001.

\section{6 - AGRADECIMENTOS}

Os autores agradecem à Coordenação de Aperfeiçoamento de Pessoal de Nivel Superior - CAPES através do Programa de Estudantes de Convênio de Pós-Graduação - PEC-PG pela concessão de bolsa, assim como à equipe do Laboratório de Virologia do Departamento de Medicina Veterinária Preventiva da Universidade Estadual de Londrina pela colaboração na parte experimental. 